\title{
Relationship of white potato to other vegetable consumption by schoolchildren and adolescents in the USA: National Health and Nutrition Examination Survey, 2003-2008
}

\author{
Lauren EW Olsho ${ }^{1, *}$ and Meenakshi M Fernandes ${ }^{2}$ \\ 'Domestic Health Division, Abt Associates Inc., 55 Wheeler Street, Cambridge, MA 02138, USA: \\ ${ }^{2}$ Social \& Economic Policy Division, Abt Associates Inc., Cambridge, MA, USA
}

Submitted 14 July 2012: Final revision received 26 November 2012: Accepted 20 December 2012: First published online 1 February 2013

\begin{abstract}
Objective: Intake of white potatoes in and out of school was estimated to provide context for a recent proposal by the US Department of Agriculture to limit provision of white potatoes in US school meals.

Design: Mean daily servings of white potatoes and other vegetables consumed in and out of school for school-aged children were estimated from two days of $24 \mathrm{~h}$ dietary recall data from the National Health and Nutrition Examination Surveys (NHANES). Total energy intake and percentage energy contribution from discretionary oils and solid fats were also estimated for all white potato dishes consumed.

Setting: The NHANES is nationally representative of the US civilian noninstitutionalized population.

Subjects: Children and adolescents aged 6-19 years ( $n$ 8466) from three combined NHANES cycles (2003-2004, 2005-2006 and 2007-2008).

Results: White potatoes represented $32 \%$ of all vegetable servings consumed by US children and adolescents. Preparations high in fats and oils, including French fries, were most popular both in and out of school. Mean consumption of white potatoes obtained from school cafeterias was approximately 0.05 servings/d among all children and adolescents, and about $0 \cdot 15$ servings/d among children and adolescents acquiring at least one item from the school cafeteria, implying current weekly intake levels well below the limit of 2 servings/week proposed by the US Department of Agriculture.

Conclusions: Although white potatoes represent a substantial proportion of vegetable consumption among school-aged children, it is unclear that proposed limits would influence white potato intake from school cafeterias. Policy makers should consider targeting preparation methods to improve the healthfulness of white potato dishes.
\end{abstract}

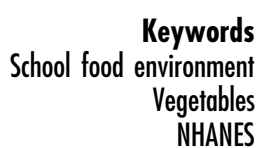

In the USA, many children and adolescents receive subsidized meals at school through the National School Lunch Program (NSLP) and the School Breakfast Program (SBP). Those from low-income households, defined as having an annual income that does not exceed $130 \%$ of the Federal Poverty Level, do not need to pay for meals if they attend a school that participates in these programmes. Children and adolescents from higher-income households may need to pay a reduced price or the full price for the subsidized meals. Approximately thirty-two million children had an NSLP school lunch and twelve million children had an SBP school breakfast in the 2010-2011 school year ${ }^{(1)}$.
Meals provided by the NSLP and the SBP must be in compliance with federal nutrition guidelines set by the US Department of Agriculture (USDA), which have historically been controversial. Most recently, in October 2011 the Senate struck down a proposed USDA rule intended to align current school nutrition standards with the Dietary Guidelines for Americans ${ }^{(2,3)}$. Among other changes, that proposal would have implemented Institute of Medicine recommendations to limit white potatoes and other starchy vegetables in the NSLP to one cup (two servings) per week, and eliminate them entirely from the SBP, in order to 'encourage students to try new vegetables in place of the familiar starchy ones ${ }^{, 4,5)}$. 
Older studies have confirmed that white potatoes comprise a substantial proportion of total vegetable intake in children and adolescents ${ }^{(6-10)}$. Furthermore, specific white potato preparations like French fries, potato chips and other preparations high in fats and oils represent a large proportion of starchy vegetable consumption, potentially contributing disproportionately to total energy intake ${ }^{(6-11)}$. Advocates therefore contend that school meals should offer reduced proportions of white potatoes and starchy vegetables relative to other vegetables. Opponents, on the other hand, argue that white potatoes themselves are nutrient-dense, particularly in healthful preparations, and that white potato consumption does not displace consumption of other vegetables ${ }^{(4,12,13)}$.

To understand the potential impact of proposed policies to limit consumption of white potatoes in school, it is important to obtain accurate descriptive information on current in-school intake levels among children and adolescents. However, to date no study has specifically assessed consumption of white potatoes acquired in and out of schools. Therefore the primary objective of the present study was to estimate the contribution of white potato intake to total vegetable intake from foods acquired in and out of school among children and adolescents. A secondary objective was to determine whether preparations lower in solid fats and discretionary oils were more prevalent in schools than in other settings.

To address these questions, child and adolescent intakes of white potatoes and other vegetables obtained from school cafeterias and other sources was assessed using the combined 2003-2008 National Health and Nutrition Examination Surveys (NHANES) ${ }^{(14)}$. In addition, energy contribution from discretionary oils and fats in different white potato dishes was estimated to assess differences in the healthfulness of preparations served across in- and out-of-school settings.

\section{Experimental methods}

US data on selected health and nutritional outcomes are collected via the NHANES by the National Center for Health Statistics (NCHS) at the Centers for Disease Control and Prevention. The NHANES collects nationally representative data for the civilian non-institutionalized US population using a multistage, clustered, probability sampling design ${ }^{(14)}$.

NHANES was conducted according to the guidelines laid down in the Declaration of Helsinki and all procedures involving human subjects were approved by the NCHS Research Ethics Review Board. Written informed consent was obtained from all NHANES respondents. All analyses reported herein were conducted using secondary, de-identified, public-use data and the present study was deemed exempt from further review by an institutional review board under US federal regulation 45 CFR $\$ 46.101(b)$.
Pooled data from three 2-year NHANES cycles, 2003-2004, 2005-2006 and 2007-2008, were used in the current analysis. NHANES participants in these study cycles completed two $24 \mathrm{~h}$ dietary recall interviews on non-consecutive days: the first by in-person interview and the second by telephone three to ten days after the first. Respondents aged 12 years and older completed the interviews on their own, while proxy-assisted interviews were conducted for children aged 6-11 years. Trained bilingual interviewers conducted interviews in English and Spanish using the USDA's computer-assisted dietary interview instrument, the Automated Multiple Pass Method ${ }^{(15)}$. A set of measuring guides was used to assist participants in reporting portion sizes ${ }^{(16)}$. Recall data were entered into Survey Net, the USDA's computerassisted food coding and data management system ${ }^{(15)}$.

For each individual food item consumed, respondents additionally reported the location from which the food was acquired. The current analysis examined intake of foods acquired in school cafeterias in comparison to foods acquired from all other locations, where other possible locations include: stores; restaurants; vending machines; cafeterias outside schools; soup kitchens, shelters and food pantries; and other sources.

The analytic sample included 16051 recalls collected from 8466 children and adolescents aged 6-19 years. The MyPyramid Equivalents Database (MPED) $2 \cdot 0$ was used to identify all NHANES foods contributing to vegetable intake, including intake from white potatoes ${ }^{(17)}$. We used the first three digits of the NHANES food code to define the following white potato dish categories for analysis: French fries, other fried potatoes, potato chips, mashed potatoes, baked/boiled potatoes, other potato preparations, mixed dishes with white potatoes, and other vegetables. Vegetable servings and grams of discretionary fats and oils for the white potato dishes were calculated using the MPED $2 \cdot 0$. Intake was averaged across the two recalls to obtain a single mean intake level for each respondent and then aggregated to produce mean intake estimates for the study population. All statistical analyses were conducted with the statistical software package Stata SE $11 \cdot 2$ using survey commands to account for the complex sampling design.

\section{Results and discussion}

Children and adolescents consumed 1·12 vegetable cupequivalents $(2 \cdot 24$ vegetable servings $)$ per day on average. Daily energy intake from white potato dishes was $481 \mathrm{~kJ}$, about $5 \%$ of total daily energy (Table 1 ).

Figure 1 presents the breakdown of vegetable servings from white potatoes and other vegetable sources. White potatoes comprised $32 \%$ of all vegetables consumed $(0 \cdot 71$ servings $)$. This finding is comparable with studies using older data ${ }^{(5,8,10)}$. French fries were the most popular white potato preparation $(0 \cdot 19$ servings $)$, followed by 
Table 1 Daily white potato consumption among US children and adolescents aged 6-19 years ( $n$ 8466), National Health and Nutrition Examination Surveys, 2003-2008

\begin{tabular}{|c|c|c|c|c|c|c|c|c|}
\hline & \multicolumn{4}{|c|}{ White potato servings } & \multicolumn{4}{|c|}{ Energy consumption } \\
\hline & \multicolumn{2}{|c|}{$\begin{array}{l}\text { From school } \\
\text { cafeteria }\end{array}$} & \multicolumn{2}{|c|}{$\begin{array}{c}\text { From outside } \\
\text { school cafeteriat }\end{array}$} & \multicolumn{2}{|c|}{$\begin{array}{l}\text { Energy from potato } \\
\text { dishes, all sources }\end{array}$} & \multirow{2}{*}{$\begin{array}{c}\% \text { of energy } \\
\text { from } \\
\text { discretionary oils }\end{array}$} & \multirow{2}{*}{$\begin{array}{c}\% \text { of energy } \\
\text { from } \\
\text { solid fats }\end{array}$} \\
\hline & Mean & $\%$ & Mean & $\%$ & $\mathrm{~kJ}$ & $\%$ & & \\
\hline French fries ${ }^{\star \star *}$ & 0.02 & 44 & $0 \cdot 17$ & 25 & 192 & 40 & 1 & 38 \\
\hline Other fried potatoes & $<0.01$ & 2 & 0.04 & 5 & 29 & 6 & 16 & 20 \\
\hline Potato chips: ${ }^{* * *}$ & 0.01 & 12 & $0 \cdot 19$ & 27 & 121 & 25 & 48 & 5 \\
\hline Mashed potatoes $\S,{ }^{* * *}$ & 0.02 & 32 & $0 \cdot 12$ & 17 & 59 & 12 & 0 & 27 \\
\hline Baked/boiled potatoes & $<0.01$ & 5 & 0.05 & 8 & 17 & 3 & 3 & 4 \\
\hline Other potato preparations $\|$ & $<0.01$ & 3 & 0.04 & 6 & 17 & 3 & 16 & 12 \\
\hline Mixed dishes with white potatoes & $<0.01$ & 1 & 0.08 & 12 & 50 & 10 & 3 & 19 \\
\hline Total & 0.05 & 100 & 0.69 & 100 & 481 & 100 & 14 & 23 \\
\hline
\end{tabular}

Column totals may differ from the sum over categories due to rounding.

Statistically significant difference in the proportion of white potato servings from school cafeterias $v$. other sources: ${ }^{\star \star \star} P<0 \cdot 001$.

tIncludes white potatoes acquired from stores, restaurants, cafeterias outside schools, vending machines, soup kitchens/shelters/food pantries, and all other locations excluding school cafeterias.

łlncludes potato stick snacks.

§lncludes stuffed potatoes and potato puffs.

IIIncludes creamed, scalloped, au gratin potatoes; potato salad; potato soup; and other dishes with potatoes.

- Includes mixed dishes in which white potatoes are not the primary ingredient, e.g. beef stew, pot pies, etc.

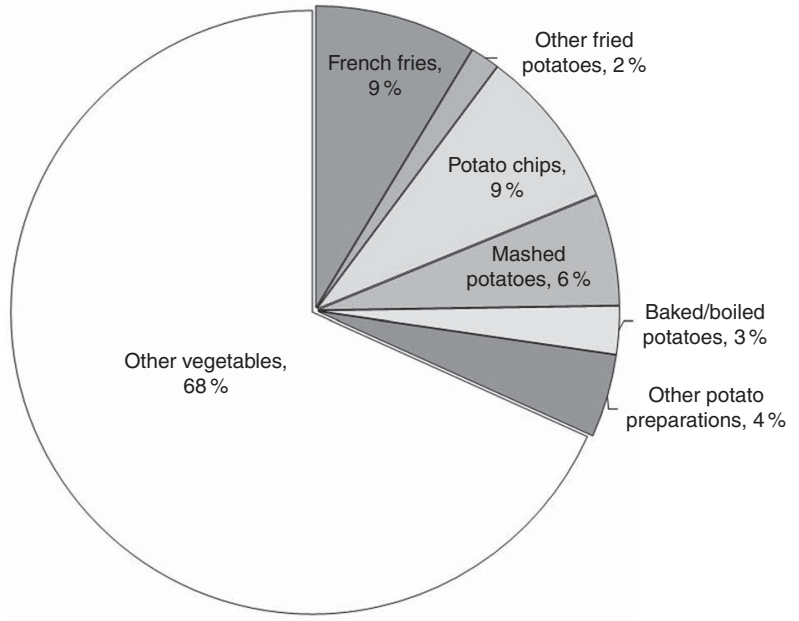

Fig. 1 Breakdown of daily vegetable servings from white potatoes and other vegetable sources among US children and adolescents aged 6-19 years ( $n$ 8466), National Health and Nutrition Examination Surveys, 2003-2008

potato chips $(0 \cdot 19$ servings), mashed potatoes $(0 \cdot 13$ servings) and baked/boiled potatoes ( 0.06 servings).

For the full sample, only about $8 \%$ of all white potatoes consumed $(0.05$ servings) were acquired from school cafeterias. However, when restricting the sample to the $36 \%$ of children and adolescents who reported consuming at least one item acquired from the school cafeteria, $21 \%$ of white potatoes consumed $(0 \cdot 15$ servings $)$ were from school cafeterias. Extrapolating over five weekdays, this implies an average weekly consumption of 0.75 white potato servings, or about 0.38 cups - well below the one-cup starchy vegetable limit previously proposed by the USDA.
Some differences in white potato preparations by source were observed: French fries $(13 \% v .8 \%, P<0.001)$ and mashed potatoes $(10 \% v .6 \%, P<0 \cdot 001)$ accounted for a larger fraction of intake from school cafeterias than from other sources, while potato chips accounted for a smaller fraction of intake from school cafeterias ( $4 \% v .9 \%$, $P<0 \cdot 001)$.

Oil and fat content varied widely across preparations. For French fries and potato chips, the two most popular potato preparations, $39 \%$ and $53 \%$ of energy, respectively, came from discretionary oils and fats. In contrast, discretionary oils and fats comprised just $7 \%$ of total energy in baked/boiled potatoes, which were among the least popular preparations.

The present analysis has several important limitations. First, because it relies on MPED $2 \cdot 0$ to calculate vegetable and discretionary fat and oil contents both for foods acquired from the school cafeteria and foods acquired elsewhere, it does not account for possible differences in recipes and preparation methods across these alternative venues. In practice, school foods often differ substantially from other foods because they are specially prepared to conform to school meal guidelines ${ }^{(8)}$. Similarly, because MPED $2 \cdot 0$ estimates were used for all three NHANES survey waves, the analysis does not account for any changes in standard preparation methods that may have occurred over the course of the 2003-2008 observation period.

\section{Conclusions}

White potatoes represent a large proportion of vegetables consumed by children and adolescents both in and out of schools. Nevertheless, total estimated weekly 
consumption of white potatoes acquired from school cafeterias appears to be well below the recently proposed USDA limit. Furthermore, our estimate of consumption of potatoes acquired in school cafeterias is likely to be an overestimate of potatoes acquired as part of the NSLP and SBP, since students could acquire potatoes from other sources in the cafeteria including à la carte lines or school fund-raising events. It is therefore unclear that the proposed rule would have reduced white potato consumption in schools.

Our results confirm that the most frequently consumed white potato dishes are higher in discretionary oils and solid fats than other preparations. However, some less popular preparations like baked potatoes have minimal discretionary oils and fats, and also may contribute to recommended intake of nutrients including vitamin $\mathrm{C}$, vitamin $\mathrm{E}, \mathrm{Fe}, \mathrm{K}$ and fibre for children and adolescents ${ }^{(11)}$. Policies seeking to influence dietary quality should take into account preparation methods ${ }^{(18)}$. Interventions specifically addressing preparation methods may increase the healthfulness of white potato dishes in school meals.

\section{Acknowledgements}

Sources of funding: This research received no specific grant from any funding agency in the public, commercial or not-for-profit sectors. Conflicts of interest: Both authors had no conflicts of interest in the preparation of this manuscript. Authors' contributions: L.E.W.O. performed all statistical analyses and contributed to manuscript drafting and revision. M.M.F. wrote the initial draft manuscript and contributed to interpretation and organization of findings. Acknowledgements: The authors gratefully acknowledge helpful comments on the draft manuscript from Bernadette Marriott, Parke Wilde, Tania Andreyeva, and attendees of the Abt Associates Inc. Journal Authors Support Group seminar.

\section{References}

1. US Department of Agriculture, Food and Nutrition Service (2012) FNS Program Data: Child Nutrition Tables. http:// www.fns.usda.gov/pd/cnpmain.htm (accessed November 2012).

2. US Department of Health and Human Services \& US Department of Agriculture (2005) Dietary Guidelines for Americans, 2005. Washington, DC: US Government Printing Office.

3. US Department of Agriculture \& US Department of Health and Human Services (2010) Dietary Guidelines for Americans, 2010. Washington, DC: US Government Printing Office.

4. Institute of Medicine of the National Academies (2009) School Meals: Building Blocks for Healthy Children. http://
www.iom.edu/Reports/2009/School-Meals-Building-Blocksfor-Healthy-Children.aspx (accessed November 2012).

5. US Department of Agriculture, Food and Nutrition Service (2012) Final Rule to the Nutrition Standards in the National School Lunch and School Breakfast Programs. http:// www.gpo.gov/fdsys/pkg/FR-2012-01-26/html/2012-1010.htm (accessed November 2012).

6. Krebs-Smith SM, Cook A, Subar AF et al. (1996) Fruit and vegetable intakes of children and adolescents in the United States. Arch Pediatr Adolesc Med 150, 81-86.

7. Kimmons J, Gillespie C, Seymour J et al. (2009) Fruit and vegetable intake among adolescents and adults in the United States: percentage meeting individualized recommendations. Medscape J Med 11, 26.

8. Condon EM, Crepinsek MK \& Fox MK (2009) School meals: types of foods offered to and consumed by children at lunch and breakfast. J Am Diet Assoc 109, 2 Suppl., S67-S78.

9. Guenther PM, Dodd KW, Reedy J et al. (2006) Most Americans eat much less than recommended amounts of fruits and vegetables. J Am Diet Assoc 106, 1371-1379.

10. Briefel RR, Wilson A \& Gleason PM (2009) Consumption of low-nutrient, energy-dense foods and beverages at school, home, and other locations among school lunch participants and nonparticipants. J Am Diet Assoc 109, 2 Suppl., S29-S90.

11. US Department of Agriculture, Food and Nutrition Service, Office of Research, Nutrition and Analysis (2008) Diet Quality of American School-Age Children by School Lunch Participation Status: Data from the National Health and Nutrition Examination Survey, 1999-2004. Report no. CN-08-NH. Alexandria, VA: FNS; available at http://www.fns.usda.gov/ora/menu/published/CNP/FILES/ NHANES-NSLP.pdf

12. Freedman MR \& Keast DR (2011) White potatoes, including french fries, contribute shortfall nutrients to children's and adolescents' diets. Nutr Res 31, 270-277.

13. Drewnowski A, Rehm C, Beals K (2011) White potatoes, non-fried, do not displace other vegetables in meals consumed by American children and adolescents aged 4-18 years (abstract). Presented at 2011 Experimental Biology Meeting, Washington, DC. http://www.potatoesin schools.com/Content/pdf/Child\%20Potato\%20Research\%201 \%20pager.pdf (accessed November 2012).

14. Centers for Disease Control and Prevention (2012) National Health and Nutrition Examination Survey Data. http://www.cdc.gov/nchs/nhanes.htm (accessed November 2012).

15. Raper N, Perloff B, Ingwersen L et al. (2004) An overview of USDA's dietary intake data system. J Food Compost Anal 17, 545-555.

16. Centers for Disease Control and Prevention (2006) MEC In-Person Dietary Interviewers Procedures Manual. http://www.cdc.gov/nchs/data/nhanes/nhanes_05_06/dietary_ mec.pdf (accessed November 2012).

17. Bowman SA, Friday JE, Moshfegh A (2008) MyPyramid Equivalents Database, 2.0 for USDA Survey Foods, 2003-2004: Documentation and User Guide. Beltsville, MD: Beltsville Human Nutrition Research Center, Agricultural Research Service, USDA; available at http://www.ars.usda. gov/Services/docs.htm?docid $=17565$

18. Monteiro C (2010) The big issue is ultra-processing. World Nutr 1, 237-269; available at http://www.wphna. org/wn_commentary_ultraprocessing_nov2010.asp 